Journal of Applied Fluid Mechanics, Vol. 6, No. 1, pp. 61-71, 2013.

Available online at www.jafmonline.net, ISSN 1735-3572, EISSN 1735-3645.

DOI: $10.36884 / \mathrm{jafm} .6 .01 .19493$

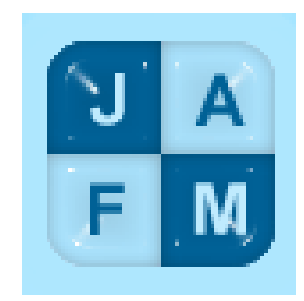

\title{
Effect of Cooling System Design on Engine Oil Temperature*
}

\author{
O. P. Singh ${ }^{\dagger}$, M. Garg, V. Kumar and Y. V. Chaudhary \\ TVS Motor Company, Hosur, Tamilnadu-635109, India \\ $\dagger$ Corresponding Author Email: om.prakashh.singh@gmail.com
}

(Received November 1, 2010; accepted November 28, 2011)

\begin{abstract}
High engine oil temperatures have detrimental effect on overall engine performance and durability. High oil temperature is a direct indication of high engine temperature and hence, the inefficient cooling system of the engine. In this paper we show how the systematic investigation of cooling system thought experiments and CFD modeling can reduce the engine oil temperature within the desirable limit. A CFD model was developed for the entire cooling system and results were validated with the experimental measurements. The CFD model and experimental measurement techniques have been described in detail. Separate experimental measurements were conducted for flow and thermal measurements and the corresponding CFD model was validated against these measurements. Various design concepts were investigated and its effects on engine heat transfer coefficients and temperatures, change in system resistances, flow rates and other parameters have been presented. A simple experimental setup was developed for optimization of the centrifugal fan. The optimized fan was then used in the CFD model. It was observed that the reduction in engine oil temperature could be achieved by systematic design changes. However, it comes at the expense of increase in system resistance.
\end{abstract}

Keywords: Engine oil temperature, Cooling system, CFD, System resistance, Heat transfer coefficient

\section{INTRODUCTION}

It is a well-known fact that engine durability and performance is directly related to the lubricating ability of engine crankcase oil, and that its lubricating ability becomes degraded with engine operation and time Schwartz et al. (1989). Apart from providing lubrication for the valvetrain and other moving parts in the engine, it also plays an important role in dissipating heat generated by the engine e.g. Huggins and Jarrett, (1963), as well as cleaning moving engine parts. Engine oil requires period changing in order to maintain proper engine operation. It is an established fact that engine oil temperature contributes significantly to the useful life of the oil. Cold oil temperature and high oil temperatures both reduce the useful operating life of oil, which a temperature within a certain range provides the longest useful oil life Vajgart et al. (1991). At high oil temperatures, antioxidants in the oil tend to become depleted, and the oil becomes more viscous and acidic due to oxidation and nitration. At low oil temperatures, fuel, water and soot tend to accumulate in the oil, reducing its viscosity and increasing wear Bolis et al. (1977a). In addition to this, acids produced by incomplete combustion reduce the ability of the oil to prevent rust and corrosion. From these discussions it comes out that keeping the oil temperature within the desirable limit is an important aspect of efficient engine operation (Bolis et al. 1977b; Caracciolo and Mcmillan, 1979).

Research in this area has shown that engine temperature play a significant part in useful life of the lubricating oil. According to the findings (Schwartz et al. 1989), engine oil temperature $\left(T_{0}\right)$ is directly related to the engine temperature $\left(T_{e}\right)$ and operating condition. The relation has the following form,

$T_{0}=k_{1}+k_{2} T_{e}+k_{3} S_{e}$

where, $k_{1}, k_{2}$, and $k_{3}$ are constants; $S_{e}$ is the engine operational speed. It is quite obvious that controlling the engine temperature can control engine oil temperature.

\footnotetext{
" This paper is based on a previous contribution in the "Design and Simulation" session at the "Small Engine Technology Conference", held at Milwaukee, WI, 2008 (Vishal Kumar, O. P. Singh, M. Garg, , Y.V Chaudhary, Optimization air Air-Cooling System of 4-Stroke Engine \# 2008-32-0071).
} 


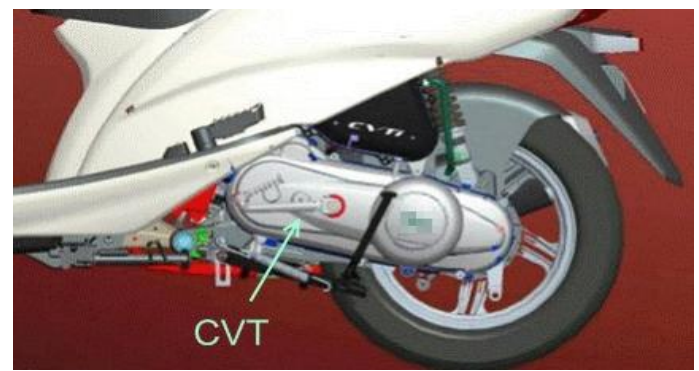

Fig. 1(a). Image of the typical scooter engine system. Engine cooling systems are not directly exposed to ambient air.

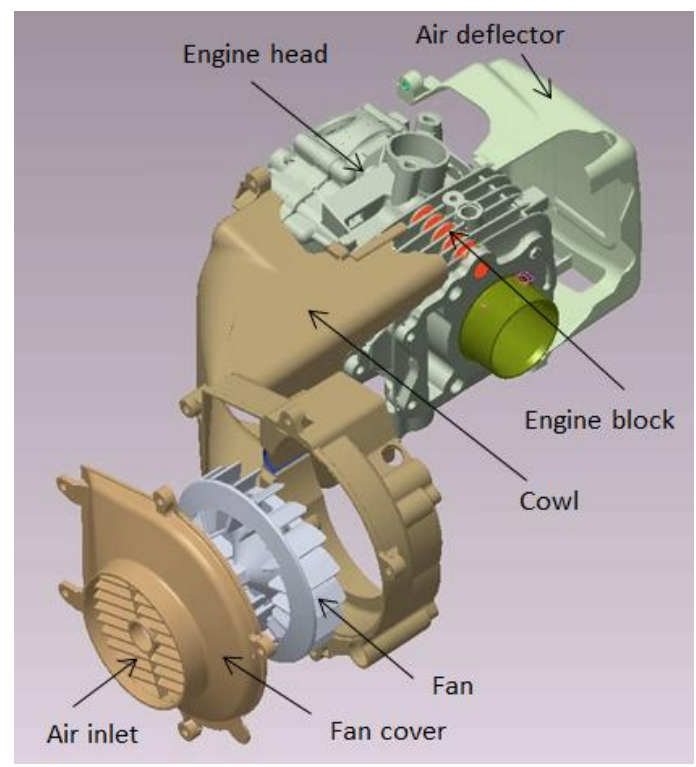

Fig. 1(b). Expanded view of the forced air-cooling system showing fan, cowl and engine.

Engine temperature in turn depends on many parameters like coolant temperature, design of cooling system, combustion, engine friction etc. (e.g. Garg et al. 2005; Coggiola et al. 1998; Vishal et al. 2008; Abdullah et al. 2008). In this paper we show that how proper cooling system design can reduce engine temperature and hence reduce engine oil temperature.

Forced air-cooling system is used in scooters because the engine is not exposed to open atmosphere (see Fig. 1(a)) like motorcycles. Generally, forced cooling system contains a centrifugal fan, fan cover, cowl or fan housing and deflector as shown in Fig. 1(b). Fan draws air from open atmosphere, pressurizes it and blows into the cowl, which guides and delivers it on the hot engine surfaces. High velocity air increases the heat transfer coefficient over the engine surfaces and thus reduces the engine temperature. Deflector guides the air towards the exit and finally to the atmosphere again. Ineffective utilization of cooling capacity of flowing air can increase the engine temperature. Engine hot surfaces must get sufficient amount of air even at the most severe engine operating conditions. Fan type air-cooling systems can consume up to $10 \%$ of the total brake power of engine Franco and Martorano, (1995). Hence it is imperative to design the engine cooling system to keep the engine oil temperature within limit.

Experiments conducted at maximum power condition on the standard scooter engine shows $140^{\circ} \mathrm{C}$ oil temperature, which is considerably high. In this paper, we present CFD (computational fluid dynamics) simulations of scooter engine cooling system and experimental results to demonstrate how proper cooling system design can reduce the engine oil temperature. Effect of cowl design and fan on engine temperature has been particularly addressed. Previous investigators have reported studies related to engine cooling. For example, Garg et al. (2005) simulated the flow in fan and cowl regions separately and derived the flow resistance curves to find the operating point of fan. Results at fan outlet were then mapped at cowl inlet. Chaua et al. (1993) did similar exercise to find out the operating point of fan. Kiura et al. (2005) validated the CFD capabilities by comparing the simulation results of fan PQ curve ( $P$ stands for pressure and $\mathrm{Q}$ for mass flow rate) against the experimental results. Later they adopted the fan model instead of actual fan in the whole cooling system simulation and the earlier measured PQ curve was provided as input. Flow results were validated against the PIV (particle image velocimetry) flow visualization results. PIV is a useful technique for flow visualization and its has been applied to study flow fields in engine components Krishna et al. (2010). In this paper, conjugate heat transfer analysis of the whole cooling is performed to find out the temperatures and heat transfer coefficients on the engine surfaces. This eliminates the need of assuming temperatures or heat transfer coefficients at the engine surfaces and hence it is more reliable. Further, fan and cooling path were simulated together in the same computational domain. The accuracy of the CFD model has been presented by comparing the results with the experimental data. Both the CFD and thermal model has been validated with the experimental measurements.

The paper is organized as follows: in section 2 CFD model is presented along with flow and thermal boundary conditions. In section 3 experimental setup and measurement results are presented. Measured results are compared with the CFD model. Various design concepts are presented in section 4 with discussion on the engine oil temperature reduction followed by conclusion in section 5 .

\section{CFD MODEL}

CFD has become an important tool for flow related investigation in various applications (Rahmati and Ashrafizaadeh, 2008; Younis et al., 2008; Ma and Wang, 2009). A single cylinder four-stroke engine having Continuously Variable Transmission (CVT) was used in this work as shown in Fig. 1(a). Specifications of the 
engine are given in table 1. Backward-curved (BC) blades fan was used in the cooling system.

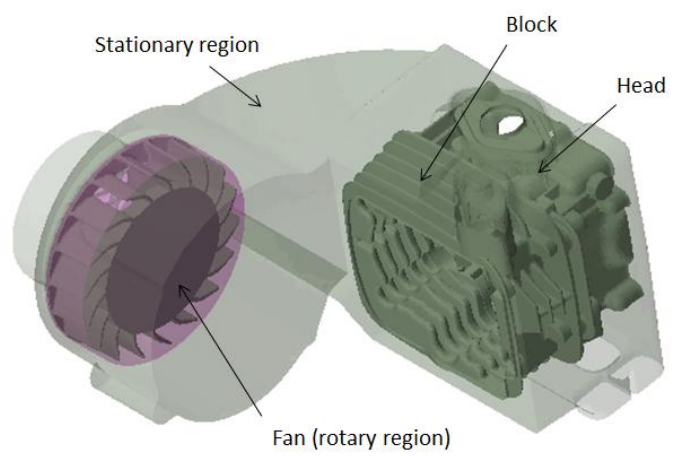

Fig. 2. Rotary and stationary regions in the CFD model.

Table 1 Engine Specifications.

\begin{tabular}{|l|c|}
\hline Displacement & $109.7 \mathrm{cc}$ \\
\hline Bore & $53.5 \mathrm{~mm}$ \\
\hline Stroke & $48.8 \mathrm{~mm}$ \\
\hline Valve Mechanism & SOHC \\
\hline Maximum Brake Power & $7 \mathrm{hp} @ 7000 \mathrm{RPM}$ \\
\hline Maximum Brake Torque & $8 \mathrm{Nm} @ 5000 \mathrm{RPM}$ \\
\hline
\end{tabular}

\subsection{Physics Modeling}

The simulation model was developed as a conjugate model where both fluid and solid regions were modeled and meshed together. Fluid continuum included the fan and cooling path, while the solid continuum included cylinder head, cylinder head cover and cylinder block. Moving and rotating parts inside the cylinder head cover like camshaft, cam chain, rocker arms, and bearings etc. were not modeled. Fluid continuum was further divided into rotary and stationary regions. Rotary region includes rotating fan, which was enveloped by a interface shell. Stationary region has fan cover, cowl and deflector. Shell serves as the interface for mass, momentum and energy transfer between rotary and stationary regions. Figure 2 depicts the rotary and stationary regions.

Moving Reference Frame (MRF) approach was used for modeling the fan rotation. MRF method adds coriolis and centrifugal forces acting at fluid cells in the rotating region to the momentum conservation equations as the momentum source terms.

\subsection{Assumptions and Approximations}

1. Atmospheric air was taken as the fluid medium, which is assumed to be constant density with ideal gas properties.

2. For modeling turbulence, Realizable k-epsilon turbulence model with wall functions was used.
3. Contact resistances between mating engine parts were assumed to be negligible and were not modeled.

4. Heat fluxes and heat transfer coefficients in the inlet and exhaust ports were calculated from 1$\mathrm{D}$ thermodynamic model of engine and the correlations available in literature respectively.

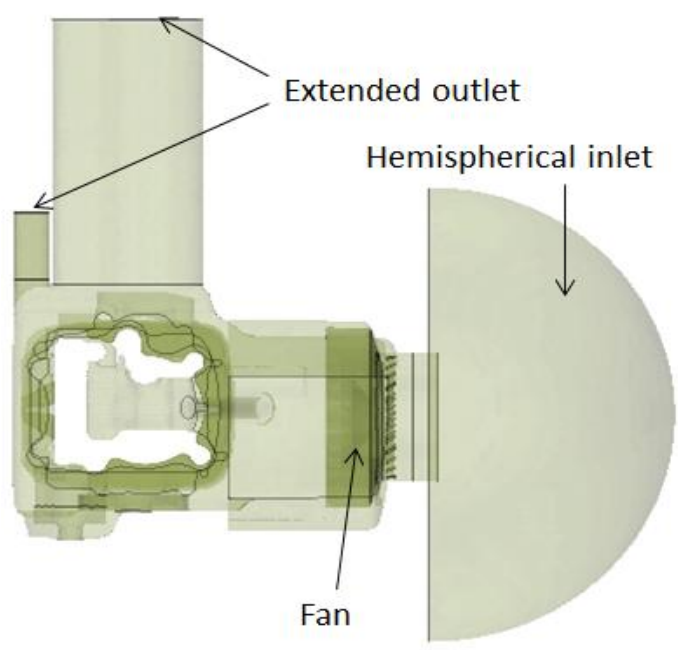

Fig. 3(a). Computational domain for CFD model.

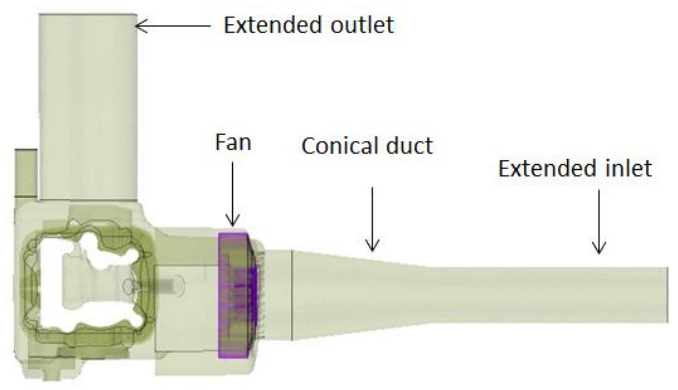

Fig. 3(b). CAD model used in experimental validation.

\subsection{CAD and CFD Mesh}

Fluid surfaces were extracted from the Computer Aided Design (CAD) and the insignificant smaller details like fillets, rounds and fasteners were ignored. Outlet(s) were extended to avoid reverse flows in numerical calculations. Two different CAD geometries were prepared for simulating the experimental flow conditions. The inlet was enlarged as a hemispherical space to simulate the atmospheric inlet conditions in the real system (Fig. 3a). To validate the experimental conditions, the inlet was extended as a conical-cylindrical duct (Fig. 3b) exactly like the experimental test rig (see section 3 ). Triangular mesh with appropriate size for each surface was adopted for surface meshing. Prism layer mesh was 
applied to the near wall regions and Polyhedral mesh was used as core mesh (Fig. 4).

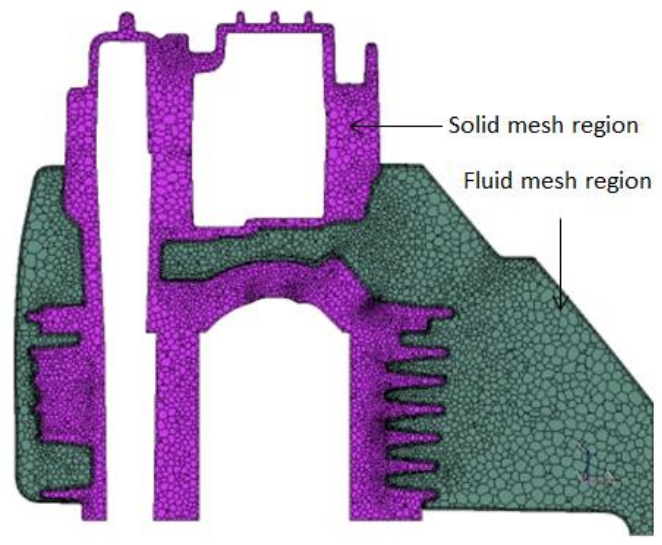

Fig. 4. A section of volume mesh showing fluid and thermal regions.

STAR-CCM+ software was used for the analysis. Realizable k-epsilon turbulence model was used to model turbulence along with wall functions. Prism layers were not generated inside solid region. External surfaces of engine, which comes in contact with air, were converted as interface. Grid independent study was carried during the validation of the CFD model. The final model has 789612 faces.

\subsection{Boundary Conditions}

\subsubsection{Flow Boundary Conditions}

As cooling system draws air from stagnant atmosphere and deliver again to atmosphere, Stagnation Inlet and Pressure Outlet boundary conditions were given to inlet and outlet(s) of simulation model respectively. RPM (revolution per minute) was given to the fan region. Other boundaries were specified as walls.

\subsubsection{Thermal Boundary Conditions}

Convection boundary condition was given at the port(s) surfaces and at those surfaces that are in contact with the engine oil. Heat flux boundary condition was applied at the combustion chamber and cylinder liner. Cylinder liner was divided into two halves and different heat fluxes were given to them. External surfaces of cylinder head, block and head cover are always in contact with cooling air and were specified as interfaces between fluid and solid regions. All fluid region surfaces were assumed to be adiabatic.

1-D thermodynamic model of the engine was prepared using AVL BOOST software and values of heat fluxes at combustion chamber and cylinder liner and gas bulk temperatures in the ports were obtained from it, which are then used in the 3-D CFD simulation model. Heat transfer coefficients in the ports were calculated using universal heat transfer correlation for intake and exhaust ports given by Depcik et al. (2002). It was assumed that oil temperature is always in thermal equilibrium with solids.

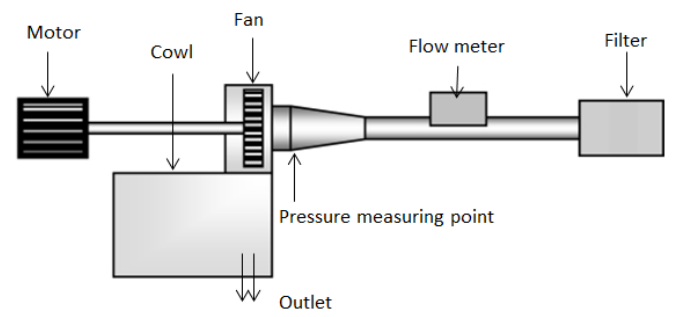

Fig. 5(a). Schematic view of the experimental test rig.

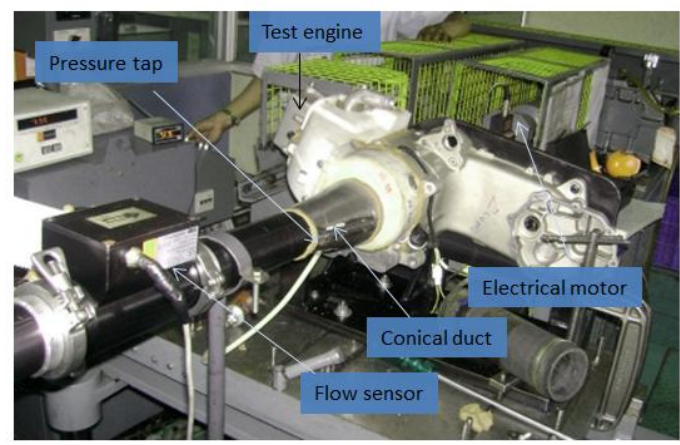

Fig. 5(b). Photograph of the experimental setup for air mass flow measurement.

\section{EXPERIMENTAl Measurement}

Experiments were conducted to obtain the flow and thermal characteristics of the engine. Figure 5(a) shows the schematic and photographic views (Fig. 5b) of the experimental rig for measuring flow parameters. The test rig consists of an engine motoring device, test engine, mass flow rate (MFR) and pressure-measuring devices. Engine was motored at low friction test rig. Only cooling system parts as described in Fig. 1(b), and crankshaft (fan is mounted at crankshaft) were used in the test engine setup and all other moving parts like piston, connecting rod, and camshaft etc. were removed to reduce the engine friction. Small gaps or leakages in the cooling path were properly sealed.

This test set up is slightly different from the actual cooling system in the manner of inducting air from atmosphere. While actual system draws air from open atmosphere, the experimental set up takes air from an air filter via a conical-cylindrical duct. As air filter is having its own resistance, the measured mass flow rate is lesser than the actual one. So, the static pressure is measured at the inlet of fan to validate the CFD results. Hot-film anemometer was used for measuring the mass flow rate. Specifications of the mass flow rate-measuring device are given in table 2. This method of measurement is based on the principle of abstraction of heat from a heated body by 
an enveloped gas flow. Static pressure was measured using a differential type water manometer.

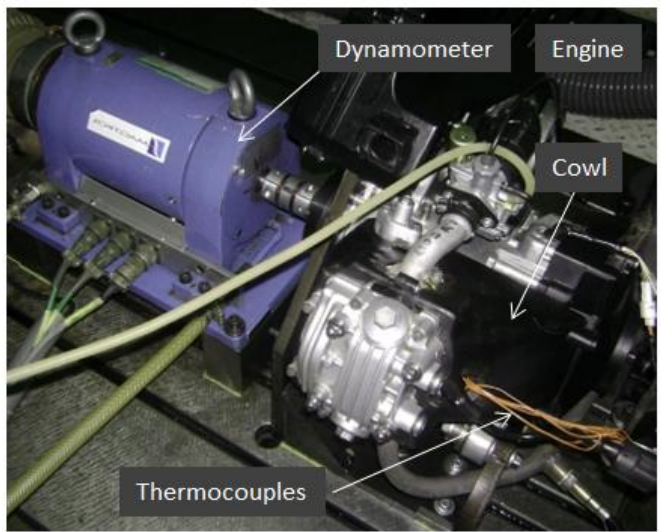

Fig. 6(a). Photograph of the engine test rig for temperature measurement.

Fan was run at 2000, 3000 and 4000 RPM and mass flow rate through the system and static pressure at fan inlet were measured. Fan could not be run beyond 4000 RPM due to the limitation of low-friction test rig. Table 3 gives the measured flow parameters at different RPM.

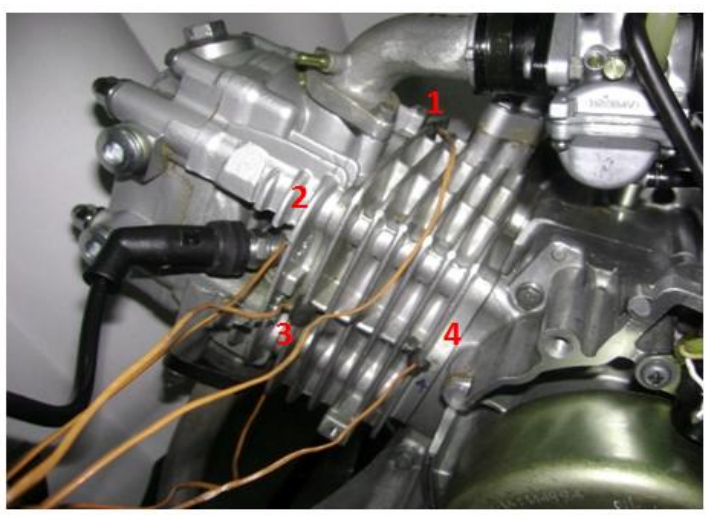

Fig. 6(b). Photograph of location of temperature measuring points.

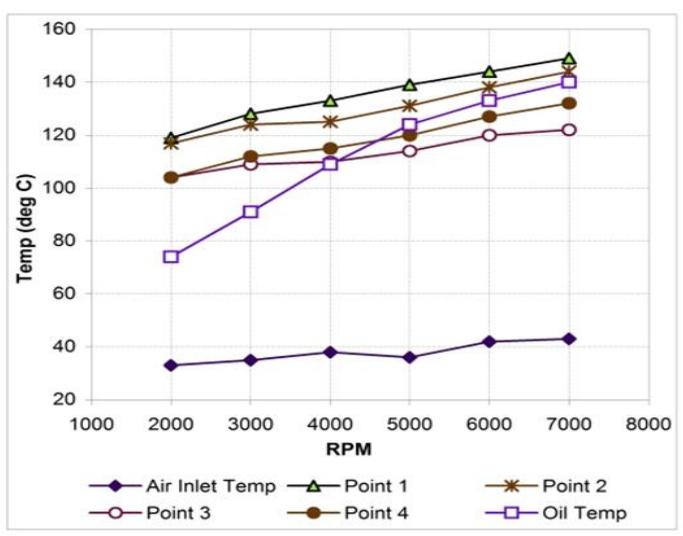

Fig. 7. Variation of measured surface and engine oil temperatures as function of engine RPM.
Another set of experiment was conducted to measure engine surfaces and engine oil temperature at Wide Open Throttle (WOT) operating condition. Engine was run at engine dynamometer at different RPM and steady-state engine oil and cylinder block surface temperatures at 4 different locations were measured using K-Type thermocouples. Fig. 6 shows the photographic view of test set-up and the locations of measuring points at cylinder block surfaces. Table 4 shows the measured temperatures. The locations of measuring points are described as following:

Location 1 - At the topmost fin of the block and below intake manifold

Location 2 - At the topmost fin of the block and below the spark plug

Location 3 - At the topmost fin of the block and below the exhaust gas pipe

Location 4 - At the second fin from bottom and elow the spark plug

Table 2 Mass flow measuring device specifications.

\begin{tabular}{|l|l|}
\hline \multicolumn{2}{|c|}{$\begin{array}{c}\text { Thermal Mass Flowmeter ABB FMT700-P } \\
\text { (Sensyflow P) }\end{array}$} \\
\hline Measuring Principle & Hot-film anemometer \\
\hline Range & 10 to $400 \mathrm{~kg} / \mathrm{h}$ \\
\hline Measuring error & $< \pm 1 \%$ of the measured value \\
\hline Repeatability & $< \pm 0.25 \%$ of the measured value \\
\hline Temperature Effect & $< \pm 0.03 \% \mathrm{~K}$ of the measured \\
\hline Pressure Effect & $< \pm 0.2 \% / 100 \mathrm{kPa}$ of the \\
\hline Response time & $\mathrm{T}_{63} \approx 12 \mathrm{~ms}$ \\
\hline
\end{tabular}

Table 3 Experimental flow results.

\begin{tabular}{|c|c|c|}
\hline RPM & Flow Rate (kg/h) & Static pressure(Pa) \\
\hline 2000 & 31.9 & 40 \\
\hline 3000 & 51.1 & 110 \\
\hline 4000 & 70.4 & 205 \\
\hline
\end{tabular}

It can be seen from Fig. 7 that temperatures are continuously increasing with RPM and maximum temperatures are seen at 7000 RPM, which is the maximum power RPM for this engine. Oil temperature is generally not allowed to go beyond $120^{\circ} \mathrm{C}$ at maximum heating condition due to its lubrication limits. Oil temperature, in this case is found to be $140{ }^{\circ} \mathrm{C}$, which is $20{ }^{\circ} \mathrm{C}$ higher that the permissible limit. 
Table 4 Measured Surface and Oil Temperatures $\left({ }^{\circ} \mathrm{C}\right)$ under engine firing condition.

\begin{tabular}{|c|c|c|c|c|c|c|}
\hline RPM & $\begin{array}{c}\text { Air Inlet } \\
\text { Temperature }\end{array}$ & $\begin{array}{c}\text { Point } \\
1\end{array}$ & $\begin{array}{c}\text { Point } \\
2\end{array}$ & 3 & 4 & Point \\
Toint & Temperature \\
\hline 2000 & 33 & 119 & 117 & 104 & 104 & 74 \\
\hline 3000 & 35 & 128 & 124 & 109 & 112 & 91 \\
\hline 4000 & 38 & 133 & 125 & 110 & 115 & 109 \\
\hline 5000 & 36 & 139 & 131 & 114 & 120 & 124 \\
\hline 6000 & 42 & 144 & 138 & 120 & 127 & 133 \\
\hline 7000 & 43 & 149 & 144 & 122 & 132 & 140 \\
\hline
\end{tabular}

\subsection{Flow Validation of CFD Model}

The simulation model for flow validation case was run at same fan RPM and pressure (atmospheric pressure) boundary conditions. Static pressure was monitored at the fan inlet and validated against the measured experimental values. Table 5 shows the comparison between experimental and simulated values.

Table 5 Comparison between measured and simulated flow values.

\begin{tabular}{|c|c|c|c|c|}
\hline RP & Flow & \multicolumn{2}{|c|}{ Static Pressure (Pa) } & $\%$ \\
\hline & & Measured & Simulated & \\
\hline 2000 & 31.9 & 40 & 45 & 12.5 \\
\hline 3000 & 51.1 & 110 & 124 & 7.0 \\
\hline 4000 & 70.4 & 205 & 214 & 4.4 \\
\hline
\end{tabular}

Error decreases as RPM increases. Higher error is seen at low RPM due to the inaccuracies in measuring manometer reading, as small pressure difference exists at low RPM. Considering the complexity of experimental model and assumptions in CFD model, errors are within the acceptable limit.

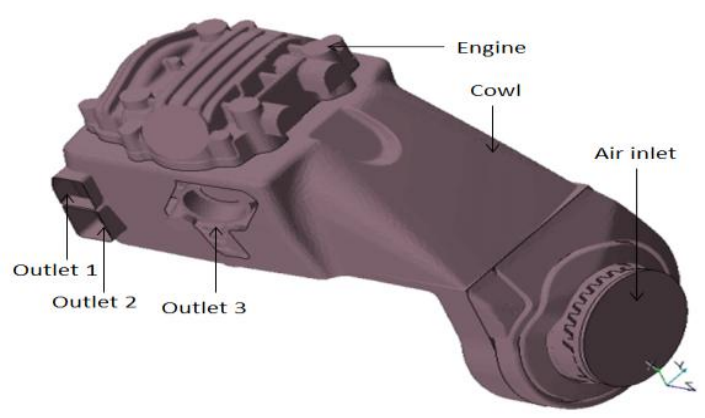

Fig. 8. CAD model showing the position of air outlets at the cowl. Fan rotates clockwise when seen from origin of coordinate system.

\subsection{Thermal Validation of CFD Model}

The numerical model was run at 7000 RPM of fan and using boundary conditions calculated from 1-D thermodynamic model of engine. Near about 1 million volume cells were used and solved with 2-processors in parallel mode for $8 \mathrm{hrs}$. It took around 3000 iterations for solution to converge. Convergence was monitored using mass flow rate and volume averaged temperature of the engine head, block and head cover. Convergence criterion was set such that the mass flow rate and temperature should become steady within $1 \mathrm{e}-5 \mathrm{~kg} / \mathrm{s}$ and $0.1{ }^{\circ} \mathrm{K}$ respectively. Heat flux boundary condition was tuned in the simulation. Table 6 gives a comparison between the experimental and simulated temperature values.

Table 6 shows the comparison with experimental and numerical model. Results are in good agreements. We used this numerical model as baseline model for further investigations.

\section{RESUlts AND Discussions}

\subsection{Flow Field Investigation}

In this section we investigate the reason of high engine oil temperatures. There are three outlets in the cowling system as shown in Fig. 8. Outlet 1 and 2 are the designed main outlets, while outlet 3 was provided due to the gap between the cowl and exhaust gas pipe. Flow \& thermal results are summarized in the table 7 given below.

Table 6 Comparison of temperatures after reducing the heat flux values.

\begin{tabular}{|c|c|c|c|c|c|}
\hline \multicolumn{7}{|c|}{ Temperatures in ${ }^{\circ} \mathrm{C}$} \\
\hline & Oil & Point 1 & Point 2 & Point 3 & Point 4 \\
\hline Experimental & 140.6 & 149 & 144 & 122 & 132 \\
\hline Simulation & 140.0 & 147 & 141 & 126 & 135 \\
\hline Difference & 0 & -2 & -3 & 4 & 3 \\
\hline
\end{tabular}

Figure 9 shows the velocity vectors at a fan section. Flow distribution is not uniform and flow shows the tendency of rushing towards the outlet 3 . Recirculation zones are observed near the wall. It can be seen that around $60 \%$ of flow is escaping from outlet 3 . Note that recirculation is reduced with variable viscosity Mukhopadhyaya (2009). However, in this case fluid is air with constant viscosity. Figure 10 show that the path towards outlet 3 has the least resistance to the flow. To reach up to outlet $1 \& 2$, flow has to take longer path surrounding the fins, which makes this path a high resistance path. Flow is getting stagnated ahead of the fins and major chunk of the flow is taking the route to outlet 3 instead of taking round and going to outlet $1 \& 2$. The stagnation of flow ahead of fins is also shown in Fig. 11. Due to this stagnation, air is not flowing over and inside the fins, which can cause 
poor heat transfer. It can also be seen that flow is sticking to the upper portion of the cowl and majority of the flow is going in the head portion, while the block fins are suffering from the lack of sufficient cooling air.

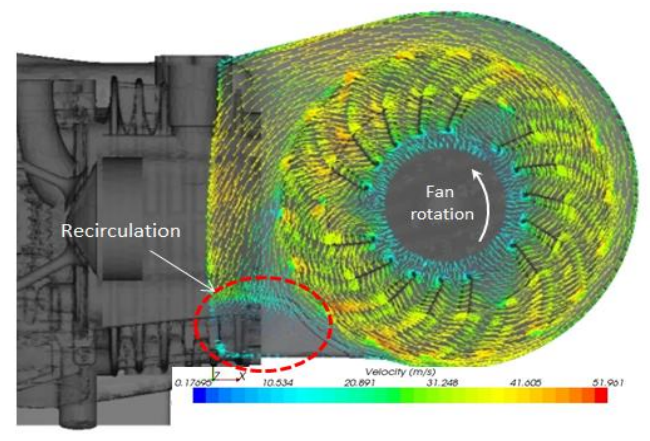

Fig. 9. Velocity vector at fan outlet.

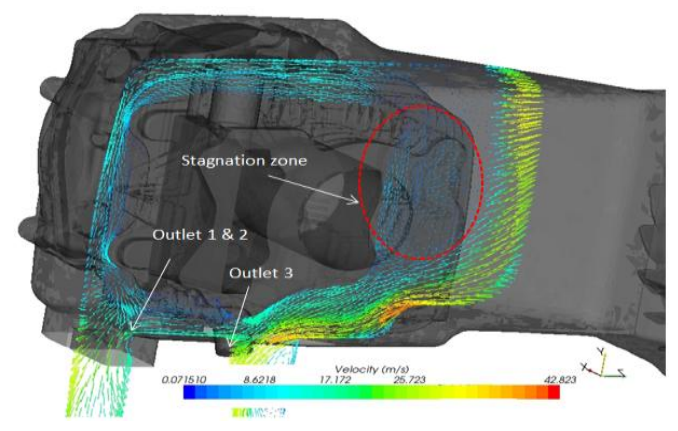

Fig. 10. Velocity vector showing non-uniform distribution of flow.

The velocity magnitudes near to wall, heat transfer coefficients and temperature distribution are shown in Fig. 12. Area near outlet 3, due to high mass flow rate, is having high velocities, high heat transfer coefficients and hence lower temperatures. At the same time, block fins are having lower velocities over them and hence higher temperatures. In the following subsections we investigate the effect of few design modifications on engine oil temperature.

\subsection{Design Considerations}

Investigation of flow fields in section 4.1 revealed that short-circuiting of the flow field and formation of stagnation regions around the engine surfaces resulted in high temperatures. The reported head and block temperatures are the volume averaged from the CFD model. In the following subsections we investigate design medications and its effect on engine oil temperature.
Table 7 Baseline simulation results. MFR denotes Mass Flow Rate, $\Delta \mathrm{P}$ - Static pressure difference between fan outlet and cooling system outlet, which is same as system resistance.

\begin{tabular}{|l|c|}
\hline Parameter & Value \\
\hline Total MFR $(\mathrm{g} / \mathrm{s})$ & 63.5 \\
\hline MFR Outlet 1 (g/s) & 14.2 \\
\hline MFR Outlet 2 (g/s) & 12.7 \\
\hline MFR Outlet 3 (g/s) & 36.6 \\
\hline Fan Moment $(\mathrm{Nm})$ & 0.161 \\
\hline$\Delta \mathrm{P}($ Pa) & 377 \\
\hline Temperature Block $(\mathrm{K})$ & 417 \\
\hline Temperature Head $(\mathrm{K})$ & 411 \\
\hline Oil Temperature $(\mathrm{K})$ & 414 \\
\hline
\end{tabular}

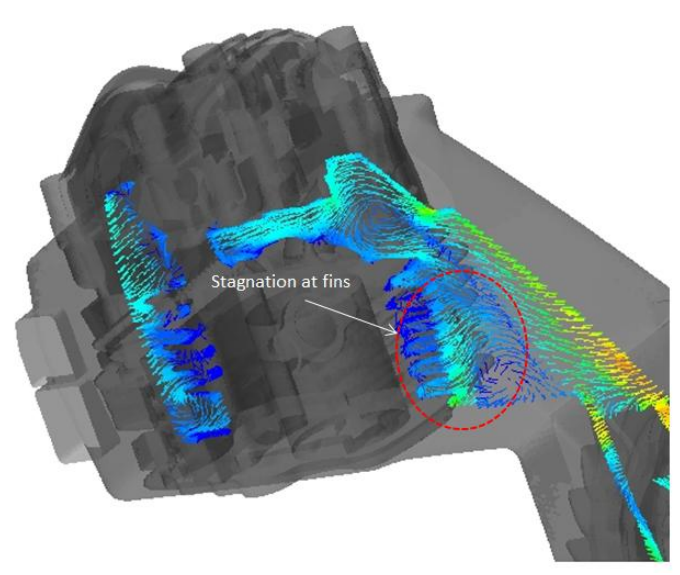

Fig. 11. Velocity vector showing stagnation regions ahead of fins.

\subsubsection{Design concept 1}

For reducing the short-circuiting of the flow, a baffle in the cowl was placed as shown in Fig. 13, which starts just at the fan outlet and goes upto block fins. The baffle divides the flow into two halves; major stream is forced to take longer path and minor stream goes towards outlet 3. The results of baffle placement are given in table 9. A reduction of $7{ }^{\circ} \mathrm{C}$ in oil temperature was achieved with baffle placement. Table 8 shows the reduction in temperatures and changes in mass flow rates at outlets. It is to be noticed that major advantage of baffle is the gain in MFR at outlet 2; increase of $13.4 \%$ is obtained. Figure 14 shows the temperature contour of cylinder block and head comparison with design concept 1 and baseline cooling system. Due to proper re-distribution of airflow, temperatures have decreases locally resulting the reduction of volume-averaged temperature of the engine. 


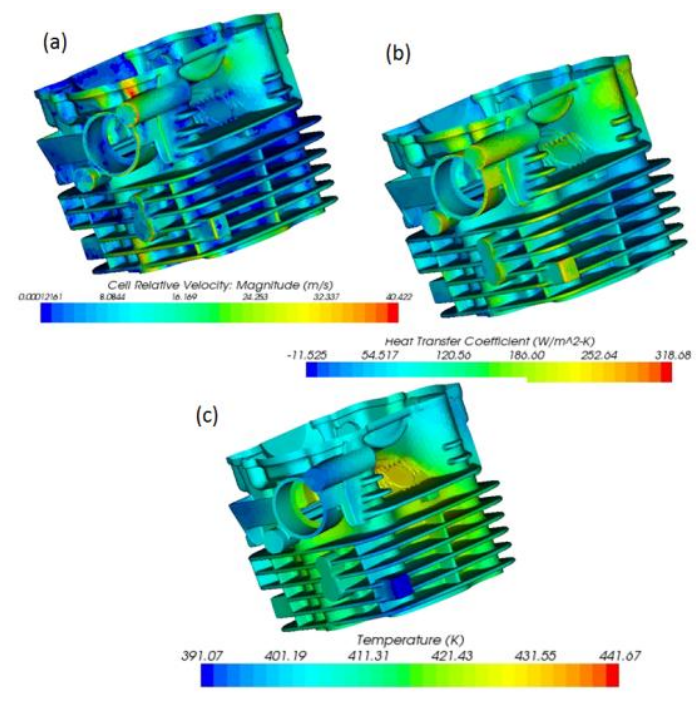

Fig. 12. (a) Velocity vector, (b) heat transfer coefficients and (c) temperatures at the engine surfaces.

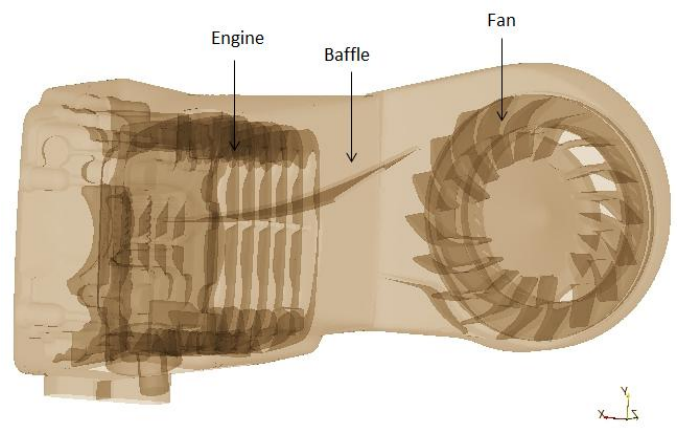

Fig. 13. Baffle placement in the cowl.

\subsubsection{Design concept 2}

In this design change, we targeted the distribution of air to flow over the cylinder block and head. Cowl shape was altered as shown in Fig. 15 to force the flow over the block fins instead going over the top towards head side. Investigation of design concept 2 was exercised along with design concept 1 . Table 9 shows combined effect of both the modifications. Following points are noted: (a) Cylinder block and head temperature reduced by $3.6 \%$ and $2.4 \%$ (desirable), (b) change in the cowl design has increased the system resistance by $21.8 \%$ i.e. pressure increased by $82 \mathrm{~Pa}$ (undesirable), (c) increase in system resistance resulted in decrease in flow rates by $9.3 \%$ (undesirable), (d) decrease in flow rates resulted in decrease in fan power consumption by $5 \%$ (desirable), and (e) the overall gain is reduction of $12.5{ }^{\circ} \mathrm{C}$ in oil temperature. Figure 16 shows the temperature contours comparison of the engine with concept design 2 with baseline cooling system. Again, significant reduction in the engine temperature can be noticed.
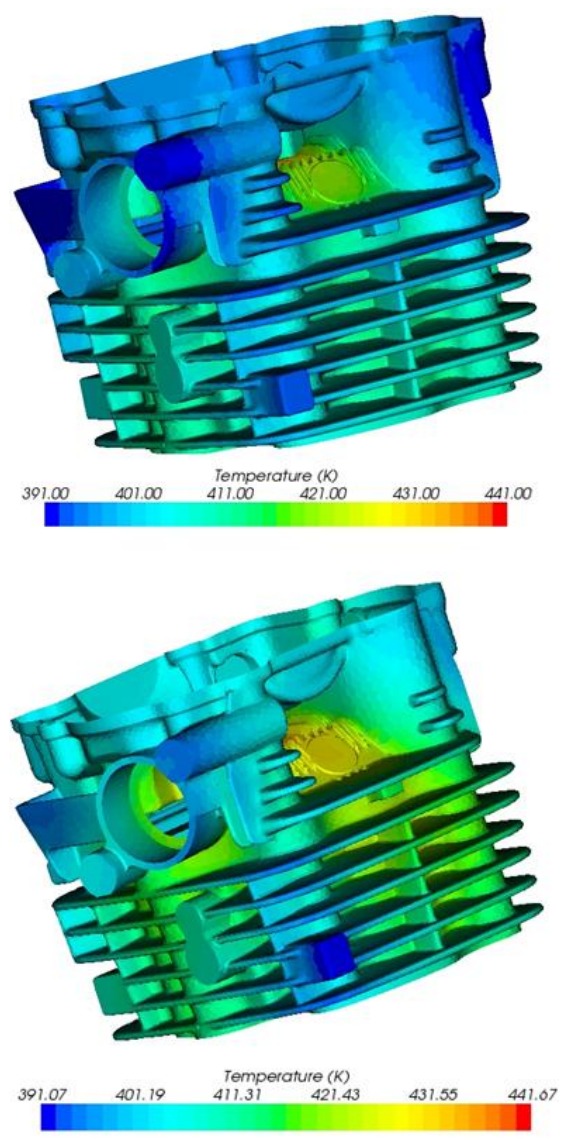

Fig. 14. Comparison of temperatures contours for design concept 1 with baseline (plotted on the same scale).

Table 8 Comparison of flow \& heat transfer results between modification 1 and baseline design.

\begin{tabular}{|c|c|c|c|}
\hline \multirow{2}{*}{ Parameter } & \multicolumn{2}{|c|}{ Value } & $\%$ Dff \\
\hline & Base & Mod 1 & \\
\hline Total MFR (g/s) & 63.5 & 63.4 & -0.2 \\
\hline MFR Outlet 1 (g/s) & 14.2 & 13.8 & -2.8 \\
\hline MFR Outlet 2 (g/s) & 12.7 & 14.4 & 13.4 \\
\hline MFR Outlet 3 (g/s) & 36.6 & 35 & -4.4 \\
\hline Fan Moment (Nm) & 0.161 & 0.160 & -0.6 \\
\hline$\Delta P(P a)$ & 377 & 373 & -1.1 \\
\hline Block Temperature(K) & 417 & 411 & -1.4 \\
\hline Head Temperature(K) & 411 & 403 & -1.9 \\
\hline Oil Temperature(K) & 414 & 407 & -1.7 \\
\hline
\end{tabular}




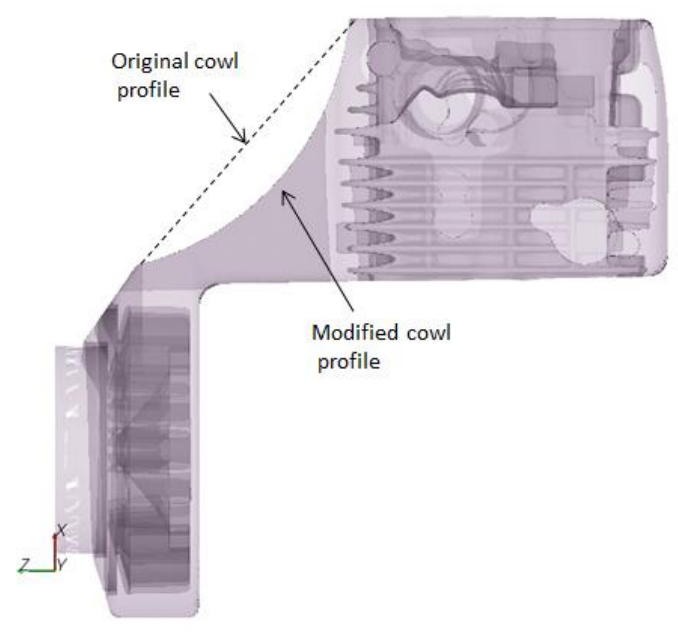

Fig. 15. New cowl shape in design concept 2.
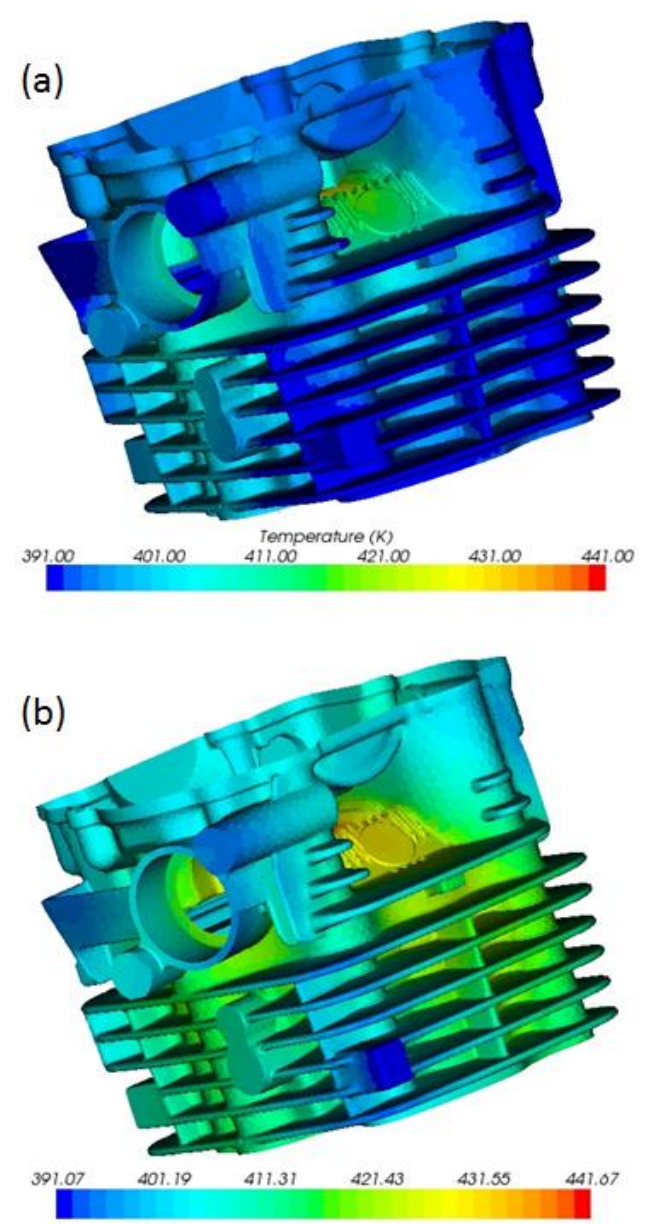

Fig. 16. Comparison of temperature contours after (a) design concept 2 with (b) baseline (plotted on same scale).
Table 9 Comparison of flow \& heat transfer results after modification 2 with baseline.

\begin{tabular}{|c|c|c|c|}
\hline \multirow{2}{*}{ Parameter } & \multicolumn{2}{|c|}{ Value } & \% Diff \\
\hline & Base & Mod 2 & \\
\hline Total MFR (g/s) & 63.5 & 57.6 & -9.3 \\
\hline MFR Outlet 1 (g/s) & 14.2 & 13.3 & -6.3 \\
\hline MFR Outlet 2 (g/s) & 12.7 & 11.4 & -10.2 \\
\hline MFR Outlet 3 (g/s) & 36.6 & 32.8 & -10.4 \\
\hline Fan Moment (Nm) & 0.161 & 0.153 & -5.0 \\
\hline$\Delta P(P a)$ & 377 & 459 & 21.8 \\
\hline Temperature Block & 417 & 402 & -3.6 \\
\hline $\begin{array}{c}\text { Temperature Head (K) } \\
\text { Oil Temperature (K) }\end{array}$ & 411 & 401 & -2.4 \\
\hline
\end{tabular}

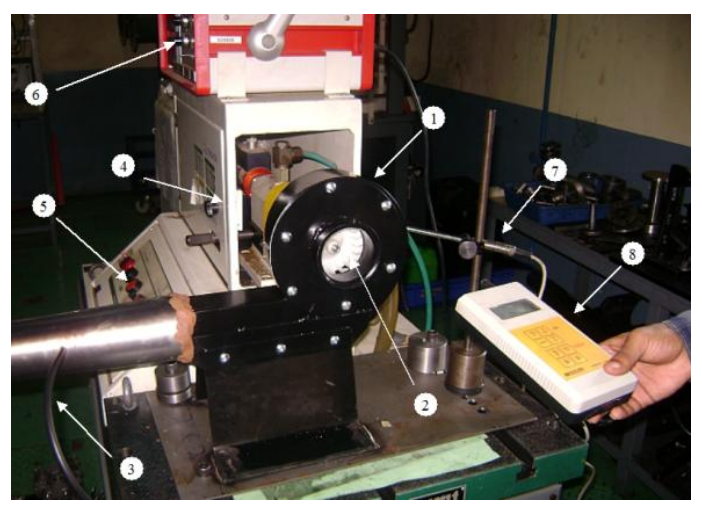

Fig. 17(a). Developed experimental setup for fan testing. The numbers in the figure denotes: (1) volute casing, (2) fan (3) tube connected from volute outlet to the U-tube manometer, (4) low friction torque measurement machine (5) RPM control switch, (6) torque value displayer unite (7) optical sensor to measure rpm, and (8) digital meter for RPM display.

\subsubsection{Design concept 3}

Heat transfer coefficient over the engine surfaces depends on the flow velocity. In design concept 3 , fan is investigated for increase in flow velocity. An experimental setup was developed (Fig. 17a) to optimize the centrifugal fan. This setup has significantly less resistance compared to the actual engine cooling system. Various blade angles and number of blades were investigated to obtain the optimized fan. Detailed results are given in the ref. Singh et al. (2011). We briefly describe the changes made in the fan. Original fan blade was having the geometrical shape as shown in the Fig. 17 (b) by red color blade. The blade inlet and outlet angles are 22 and 44 degree from radial direction 
respectively. Blade inlet diameter is $33 \mathrm{~mm}$. It was found from the baseline simulation that flow enters the blade at an inlet angle of $52 \mathrm{deg}$ from radial direction as shown by blue arrow in Fig. 17. To make the flow entry shockfree and smooth, blade inlet angle was changed from 22 deg to $52 \mathrm{deg}$. Further, to increase the component of absolute velocity in radial direction at outlet, which governs the mass flow rate, outlet angle is reduced from $44 \mathrm{deg}$ to $34 \mathrm{deg}$. Fan inlet radius was decreased from 33 $\mathrm{mm}$ to $25 \mathrm{~mm}$.

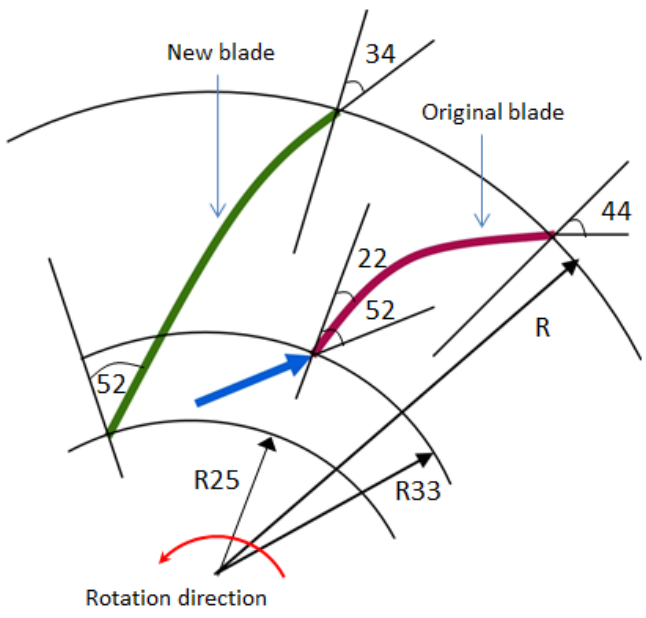

Fig. 17(b). Original and modified blade shape (angles in degree and dimensions are in $\mathrm{mm}$ )

Table 10 Comparison of flow \& heat transfer results after modification 3 with baseline.

\begin{tabular}{|c|c|c|c|}
\hline \multirow[t]{2}{*}{ Parameter } & \multicolumn{2}{|c|}{ Value } & $\%$ Diff \\
\hline & Base & Mod 3 & \\
\hline Total MFR (g/s) & 63.5 & 62.8 & -1.1 \\
\hline MFR Outlet $1(\mathrm{~g} / \mathrm{s})$ & 14.2 & 13.9 & -2.1 \\
\hline MFR Outlet $2(\mathrm{~g} / \mathrm{s})$ & 12.7 & 12.5 & -1.6 \\
\hline MFR Outlet $3(\mathrm{~g} / \mathrm{s})$ & 36.6 & 36.4 & -0.5 \\
\hline Fan Moment $(\mathrm{Nm})$ & 0.161 & 0.156 & -3.1 \\
\hline$\Delta \mathrm{P}(\mathrm{Pa})$ & 377 & 550 & 45.9 \\
\hline $\begin{array}{l}\text { Block Temperature } \\
(\mathrm{K})\end{array}$ & 417 & 391 & -6.2 \\
\hline $\begin{array}{l}\text { Head Temperature } \\
(\mathrm{K})\end{array}$ & 411 & 389 & -5.4 \\
\hline Oil Temperature (K) & 414 & 390 & -5.8 \\
\hline
\end{tabular}

Both of above-mentioned modifications in blade angles were incorporated over the base fan design and the resultant fan blade is shown in green color in Fig. 17(b). This modification in fan design was combined with modification 1 and 2 of cowl and the results are shown in table 10. It can be seen that modification 3 has reduced the oil temperature by $24{ }^{\circ} \mathrm{C}$. This comes at the expense of increase in system resistance. It signifies that flow is now 'seeing' more surfaces and that is why we observed $6.2 \%$ and $5.4 \%$ reduction in engine block and head temperatures. The final design of the cooling system was implemented for the mass production of the vehicle.

\section{CONClusion}

It has been demonstrated in this paper that engine oil temperature can be controlled by suitable design modifications in the cooling system without employing additional accessories. Design modifications on the cooling system components: cowl and fan was investigated using a validated CFD model. Baffle on the cowl reduced the oil temperature by $7^{\circ} \mathrm{C}$. Cowl design was further modified to direct the flow on the engine block that reduced oil temperature by $12.5^{\circ} \mathrm{C}$. Re-design of the centrifugal fan provided the overall reduction of $24^{\circ} \mathrm{C}$ oil temperature. The interesting part of the investigation was that reduction in oil temperature was achieved at the expense of increase in system resistance. We hope that the systematic methodology presented in the paper would serve as an useful guide to the engine designers and computational analysis engineers to develop CFD models and experimental set for validation and carry out systematic investigation on the root cause of the high temperature related problems in engines.

\section{REFERENCES}

Abdullah, S., Kurniawan, W. H., and Shamsudeen, A. (2008). Numerical analysis of the combustion process in a compressed natural gas direct injection engine, $J$. App. Fluid Mech., 1(2). 66-86.

Bolis, D. A., Johnson, J. H. and Donald, A. (1977a), Daavetilla, The effect of oil and coolant temperatures on diesel engine wear, SAE paper \# 770086.

Bolis, D. A., Johnson, J. H., and Callen, R., (1977b). A study of the effect of oil and coolant temperatures on diesel engine brake specific fuel consumption, $S A E$ paper \# 770313.

Caracciolo F., and Mcmillan, M. L. (1979), Effect of engine oil viscosity on low-temperature cranking, starting, and fuel economy, SAE paper \# 790728.

Chaua K., Bilanin, A. J., and M. E. Olson (1993). Engine compartment heat rejection analysis via navier- stokes simulations. SAE paper \# 932971.

Coggiola Éric, Dessale, B., Robert Broberg, S.M., and Bakir, F. (1998). CFD based sesign for automotive engine cooling fan systems, SAE paper \# 980427. 
O. P. Singh et al. / JAFM, Vol. 6, No. 1, pp. 61-71, 2013.

Depcik, C., and Assanis, D. (2002). A universal heat transfer correlation for intake and exhaust flows in spark-ignition internal combustion engine. $S A E$ Paper \# 2002-01-0372.

Franco, A. and Martorano, L. (1995). Principles for optimization of air cooling system applied to the twostroke engine. SAE paper \# 951798.

Frank, P. Bleier (1997) Fan Handbook, McGraw-Hill, First, p. 5.5.

Garg, M., Kumar, O. H., Prasad, N., and Swamy, V., (2005). Experimental and CFD simulation-based analytical optimization of air-cooling system for a small 4-stroke scooter engine. SAE paper \# 200532-0026.

Huggins H.D., and Jarrett, N. (1963). Oil cooling - its effect on engine cooling systems, SAE paper \# 630317.

Kiura T., T. Kushibiki, and K. Shiomi (2005). Research on prediction of cooling air flow in small air-cooled utility engines. SAE paper \# 2005-32-0023.0

Krishna, B.M., and Mallikarjuna, J.M., (2010). Characterisation of flow through the intake valve of a single cylinder engine using particle image velocimetry, J. App. Fluid Mech. 3(2). 23-32.

Ma, R., Wang, K., (2008). CFD numerical simulation and experimental study of effects of screw-sleeve fitting clearance upon triangular thread labyrinth screw pump (LSP) performance, J. App. Fluid Mech. 3(1). 75-81.
Mukhopadhyay, S., (2009). Effects of radiation and variable fluid viscosity and flow and heat transfer along a symmetric wedge, J. App. Fluid Mech. 2(2). 29-34.

Rahmati, A. R., and Ashrafizaadeh, M. (2008). A generalized lattice boltzmann method for threedimensional incompressible fluid flow simulation, $J$. App. Fluid Mech. 2(1). 71-96.

Schwartz et al. (1989). Automatic engine oil change indicator system, U.S patent no. 4847769, Jul. 11.

Singh, O.P., Khilwani, R., Sreenivasulu, T. and Kannan, M. (2010). Influence of geometric parameters on centrifugal fan performance and its significant in automotive applications, Int. j. adv. eng. \& technol., 1(2), 2011.

Vajgart et al. (1991) Method and apparatus for determining engine oil change intervals according to actual engine use, U.S patent no. 5060156.

Vishal, K., Singh, O. P., Manish, G. and Yatin, V. C., (2008). Optimization of Air-Cooling System of 4Stroke Scooter Engine, SAE paper \# 2008-32-0071.

Younis Y., Bibi, A., Haque, A.U. and Khushnood, S., (2008). Vortical flow topology on windward and leeward side of delta wing at supersonic speed, $J$. App. Fluid Mech. 2(2). 13-21. 